\title{
ChemComm
}

Check for updates

Cite this: Chem. Commun., 2020, 56, 14821

Received 5th August 2020,

Accepted 15th October 2020

DOI: 10.1039/d0cc05337f

rsc.li/chemcomm

Addition of HOTf to a mixture of Co' $\mathrm{CO}^{\text {III }}(\mathrm{BDPP})\left(\mathrm{O}_{2}{ }^{\circ}\right)\left(1, \mathrm{H}_{2} \mathrm{BDPP}=2,6\right.$ bis((2-(S)-diphenylhydroxylmethyl-1-pyrrolidinyl)methyl)pyridine) and $\mathrm{Cp}_{2}{ }_{2} \mathrm{Fe}$ produced $\mathrm{H}_{2} \mathrm{O}_{2}$ in high yield implying formation of Co"'(BDP$\mathrm{P})(\mathrm{OOH})(3)$, and reaction of $\mathrm{Sc}(\mathrm{OTf})_{3}$ with the same mixture gave a peroxo-bridged $\mathrm{Co}^{\prime \prime \prime} / \mathrm{Sc}^{\prime \prime \prime} 5$. These findings demonstrate the ambiphilic property of Co'"'-superoxo 1.

Metal-superoxo species are often believed to be the first intermediate following dioxygen $\left(\mathrm{O}_{2}\right)$ association in the catalytic cycle of $\mathrm{O}_{2}$ activating metalloenzymes. ${ }^{1}$ Despite intensive work in the past, the chemistry of metal-superoxo complexes remains largely unexplored, and hence attracts significant attention from chemists and biochemists. ${ }^{2}$ Inter alia, metal-superoxo intermediates can react with $\mathrm{NO}^{\bullet}$ or organic radicals to furnish metal-peroxynitrite ${ }^{3}$ and -alkylperoxo ${ }^{4}$ complexes via radical coupling. Furthermore, they exhibit considerable electrophilicity as indicated by their capability of performing hydrogen atom abstraction (HAA) ${ }^{5}$ from weak $\mathrm{C}-\mathrm{H}$ and $\mathrm{O}-\mathrm{H}$ bonds and oxygen atom transfer ${ }^{6}$ to triphenylphosphine or thiol anisoles. On the other hand, they can initiate deformylation processes when treated with 2-phenylpropionaldehyde, thereby revealing their nucleophilic character. ${ }^{7,8}$ Besides the aforementioned well know activities, in a given elementary transformation metal-superoxo intermediates may function not only as an electrophile but also as a nucleophile. In fact, ambiphilicity

\footnotetext{
${ }^{a}$ Department of Chemistry, National Taiwan Normal University, Taipei 11677, Taiwan.E-mail:wzlee@ntnu.edu.tw

${ }^{b}$ Universität Göttingen, Institut für Anorganische Chemie, D-37077 Göttingen, Germany.E-mail: franc.meyer@chemie.uni-goettingen.de

${ }^{c}$ Max-Planck-Institut für Chemische Energiekonversion, Mülheim an der Ruhr D-45470, Germany.E-mail: eckhard.bill@cec.mpg.de

${ }^{d}$ State Key Laboratory of Catalysis, Dalian Institute of Chemical Physics, Chinese Academy of Sciences, Dalian 116023, China. E-mail: shengfa.ye@dicp.ac.cn

${ }^{e}$ Max-Planck-Institut für Kohlenforschung, Mülheim an der Ruhr, D-45470, Germany. E-mail: shengfa.ye@kofo.mpg.de

${ }^{f}$ Department of Medicinal and Applied Chemistry, Kaohsiung Medical University, Kaohsiung 807, Taiwan

$\dagger$ Electronic supplementary information (ESI) available. See DOI: 10.1039/ docc05337f
}

of metal-superoxo species has been postulated in a series of theoretical and experimentally investigations including $\mathrm{O}_{2}$ activation catalyzed by $\alpha$-ketoglutarate dependent dioxygenases, ${ }^{9}$ and by $\mathrm{Cu}, \mathrm{Fe}$ and $\mathrm{Co}$ model complexes. ${ }^{10}$ Only recently has such ambiphilic property been experimentally confirmed. ${ }^{8}$ In our continuing efforts devoted to investigating reactivity of metalsuperoxo intermediates, some of us succeeded in preparing a range of homologous $\mathrm{Fe}^{\mathrm{III}}$-, $\mathrm{Co}^{\mathrm{III}}$ - and $\mathrm{Mn}^{\mathrm{III}}$-superoxo species by reacting $\mathrm{O}_{2}$ with the corresponding divalent precursors. ${ }^{11}$ It has been shown that these trivalent metal-superoxo complexes can convert into the metal-hydroperoxo complexes via HAA. In particular, the reaction of $\mathrm{Mn}^{\mathrm{III}}\left(\mathrm{BDP}^{\mathrm{Br}} \mathrm{P}\right)\left(\mathrm{O}_{2}{ }^{\bullet}\right)\left(\mathrm{H}_{2} \mathrm{BDP}^{\mathrm{Br}} \mathrm{P}=2,6-\mathrm{bis}((2-(S)-\right.$ di(4-bromo)-phenylhydroxylmethyl-1-pyrrolidinyl)methyl)pyridine) with trifluoroacetic acid (TFA) and $\mathrm{Sc}(\mathrm{OTf})_{3}$ yields rare examples of $\mathrm{Mn}^{\mathrm{IV}}$-hydroperoxo complexes, $\mathrm{Mn}^{\mathrm{IV}}\left(\mathrm{BDP}^{\mathrm{Br}} \mathrm{P}\right)(\mathrm{OOH})$, and $\left[\mathrm{Mn}^{\mathrm{IV}}(\mu-\mathrm{OO})\right.$ $\left.\mathrm{Sc}(\mathrm{OTf})_{n}\right]^{(3-n)+}$ as evidenced by the combined spectroscopic and computational studies (Scheme 1). ${ }^{8}$ Obviously, these proton- and metal-coupled electron transfer processes provide the first experimental support for the proposed ambiphilicity of metal-superoxo species. In this regard, more examples are desired to fully understand how the ambiphilic property of metal-superoxo species affects their chemical reactivity. To this end, we examined the reaction of a Co ${ }^{\mathrm{III}}$-superoxo complex, $\mathrm{Co}^{\mathrm{III}}(\mathrm{BDPP})\left(\mathrm{O}_{2}{ }^{\bullet}\right)\left(\mathbf{1}, \mathrm{H}_{2} \mathrm{BDPP}=2,6-\mathrm{bis}((2-\right.$ $(S)$-diphenylhydroxylmethyl-1-pyrrolidinyl)methyl)pyridine) with TFA and $\mathrm{Sc}(\mathrm{OTf})_{3}$ together with external electron donors.

Treating 1 with HOTf in THF at $-90{ }^{\circ} \mathrm{C}$ gave a gray-green solution attributed to intermediate 2 having two weak absorption bands at 470 and $640 \mathrm{~nm}$, which reached maxima when 1 equiv. of HOTf was added (the inset of Fig. 1). The existence of an isosbestic point at 590 suggested that no intermediate was formed in the course of conversion of 1 to 2 (Fig. 1). Conversely, complex 1 can be retrieved from deprotonation of 2 by 1 equiv. of 1,8diazabicyclo[5.4.0] undec-7-ene (DBU) with a yield of $80 \%$ with respect to 1 (Fig. S1, ESI $\dagger$ ). Moreover, complex 2 can be obtained from one-electron oxidation of the hydroperoxo complex $\mathrm{Co}^{\mathrm{III}}$ (BDP$\mathrm{P})(\mathrm{OOH})(3)$. Adding equimolar of tris(4-bromophenyl)ammoniumyl hexachloroantimonate, which is often referred to as magic blue, to a THF solution of 3 at $-90{ }^{\circ} \mathrm{C}$ resulted in a gray-green solution, whose 


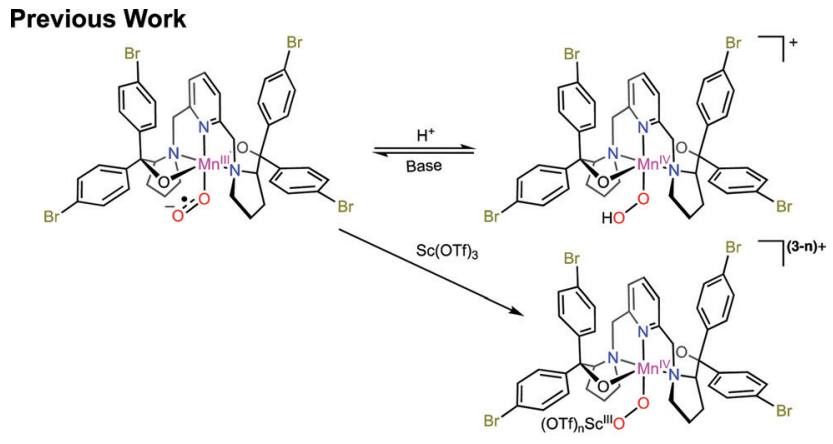

This Work

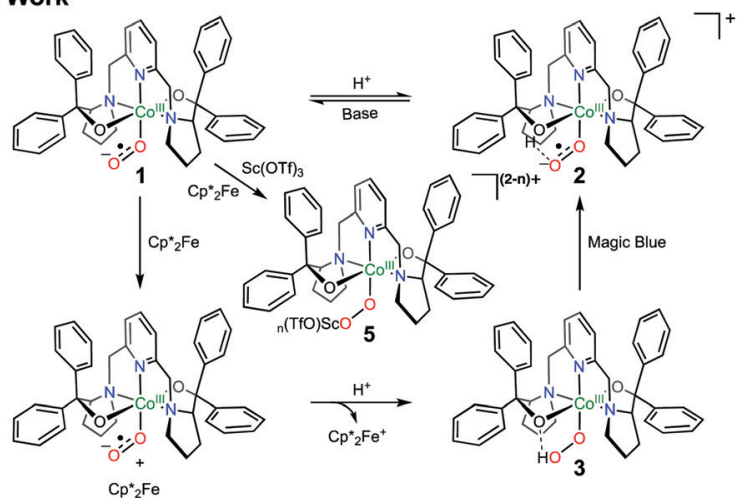

Scheme 1 Ambiphilicity of metal-superoxo complexes.

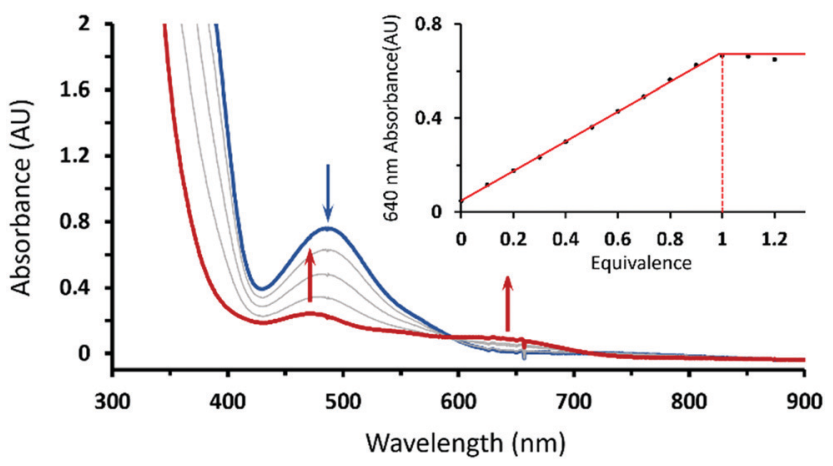

Fig. 1 UV-vis spectral changes of the reaction of $1(1.0 \mathrm{mM}$, blue trace) with 1 equiv. of HOTf in THF at $-90^{\circ} \mathrm{C}$. Inset: Titration curve of 1 with HOTf. $X$-axis: the equivalents of HOTf, $Y$-axis: the conversion ratio of the absorption peak at $640 \mathrm{~nm}$.

absorption spectrum displayed the same signature features as those found for 2 (Fig. S2, ESI $\dagger$ ).

To identify the exact nature of the resulting species 2 , we have undertaken detailed spectroscopic characterization and DFT calculations. The EPR measurement of 2 exhibited a spectrum similar to that of $\mathbf{1}\left(A_{\mathrm{Co}}=18 \mathrm{G}\right)$ except for a slightly larger ${ }^{59} \mathrm{Co}$ hyperfine coupling constant $\left(A_{\mathrm{Co}}=24 \mathrm{G}\right)$ seen in Fig. 2, thus indicating that 2 still consists of a $\mathrm{Co}^{\mathrm{III}}$ center coupled with a radical ligand yielding an overall doublet ground state. The radical ligand thus would be a hydroperoxyl radical or a superoxo having a strong hydrogen bonding interaction with the protonated $\mathrm{BDPP}^{2-}$ ligand (Scheme 1) as

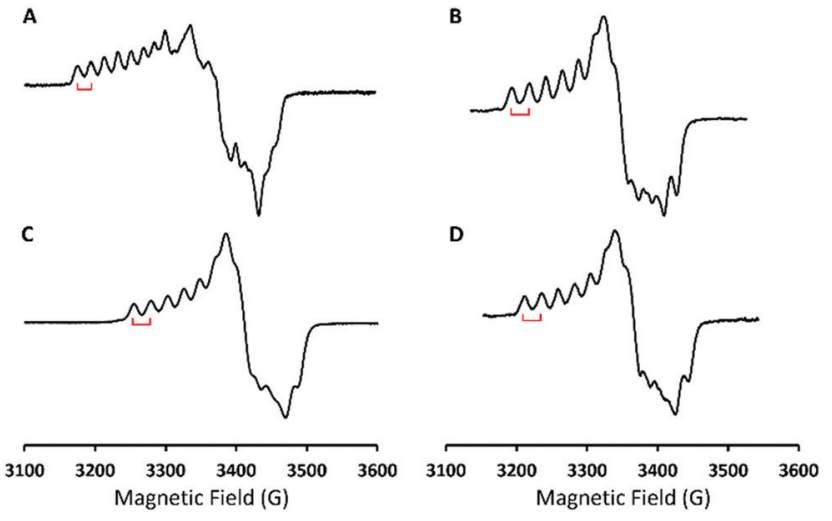

Fig. 2 X-band EPR spectra of (A) $1\left(g_{1}=2.098, A_{\mathrm{Co}_{\mathrm{O}}}=18 \mathrm{G}\right)$; (B) 1 with 1 equiv. of HOTf $\left(g_{1}=2.066, A_{C o}=24 \mathrm{G}\right)$; (C) 1 with 1 equiv. of DOTf $\left(g_{1}=2.064, A_{\mathrm{Co}}=24 \mathrm{G}\right)$ and (D) 1 with 1 equiv. of $\mathrm{Sc}(\mathrm{OTf})_{3}\left(g_{1}=2.066\right.$, $\left.A_{\text {Co }}=24 \mathrm{G}\right)$. Measurement condition: $T=77 \mathrm{~K}, f_{\mathrm{mw}}=9.6 \mathrm{GHz}$.

suggested by the crystal structure of $3 .^{11 b}$ However, the EPR spectrum of the product generated by reacting 1 with deuterated triflate acid (DOTf) is almost identical to that of 2 without discernable line broadening, which essentially rules out the possibility of the radical ligand being a hydroperoxyl radical (Fig. 2C). Repeated attempts to obtain the $\mathrm{O}-\mathrm{O}$ vibrational frequencies of 2 from resonance Raman measurements did not accomplish, largely because 2 has only weak chromophores in the usual UV-vis region (Fig. 1). Consequently, the intensity of the $\mathrm{O}-\mathrm{O}$ stretching signal is too low to be readily detected.

DFT calculations also suggested the $\mathrm{O}$ donor of the $\mathrm{BDPP}^{2-}$ ligand to be the favored protonation site of $\mathbf{1}$, consistent with experiment. Even when the starting geometry contained a $\mathrm{OOH}$ ligand in which the distal $\mathrm{H}$ atom forms a hydrogen bond with the $\mathrm{BDPP}^{2-}$ ligand, the geometry optimizations invariably shifted the $\mathrm{H}$ atom back to the $\mathrm{O}$ atom of $\mathrm{BDPP}^{2-}$ and eventually converged to A (Fig. 3). We also tested the initial geometry without the hydrogen bond by tilting the $\mathrm{H}$ atom upward. The computations indeed yielded a $\mathrm{Co}^{\mathrm{III}}$ center bound to a hydroperoxyl radical ligand (C), but $\mathbf{C}$ lies $23.2 \mathrm{kcal} \mathrm{mol}^{-1}$ higher in energy above A (Fig. 3). Moreover, formation of a hydrogen bond between the superoxo motif and the proton of the $\mathrm{OH}$ group of the protonated $\mathrm{BDPP}^{2-}$ ligand stabilized $\mathbf{A}$ by $10.4 \mathrm{kcal} \mathrm{mol}^{-1}$ relative to $\mathbf{B}$ (Fig. 3 ). Thus, $\mathbf{A}$ is best deemed as the most appropriate model for 2 .

Alternatively, to transform 1 into the corresponding peroxo product, we then added 1 equiv. of decamethylferrocene $\left(\mathrm{Cp}_{2}{ }_{2} \mathrm{Fe}\right)$ or sodium naphthalenide $\left(\mathrm{NaC}_{10} \mathrm{H}_{8}\right)$ to THF solutions of 1 at $-90{ }^{\circ} \mathrm{C}$, but UV-vis measurements suggested that no reactions occurred (Fig. S3 and S4, ESI $\dagger$ ). Taken together, neither proton nor electron donors alone can realize the superoxo-to-peroxo conversion for $\mathbf{1}$.

Interestingly, upon treating a mixture containing equimolar 1 and $\mathrm{Cp}^{*}{ }_{2} \mathrm{Fe}$ with 1 equiv. of HOTf, the color of the reaction solution gradually changed from gray-green to dark green then orange; meanwhile, characteristic features of decamethylferrocenium $\left(\mathrm{Cp}^{*}{ }_{2} \mathrm{Fe}^{+}\right)$emerged suggesting that $\mathrm{Co}^{\mathrm{III}}$-superoxo 1 was reduced in the presence of both HOTf and $\mathrm{Cp}_{2}^{*} \mathrm{Fe}$ (Fig. 4A). 


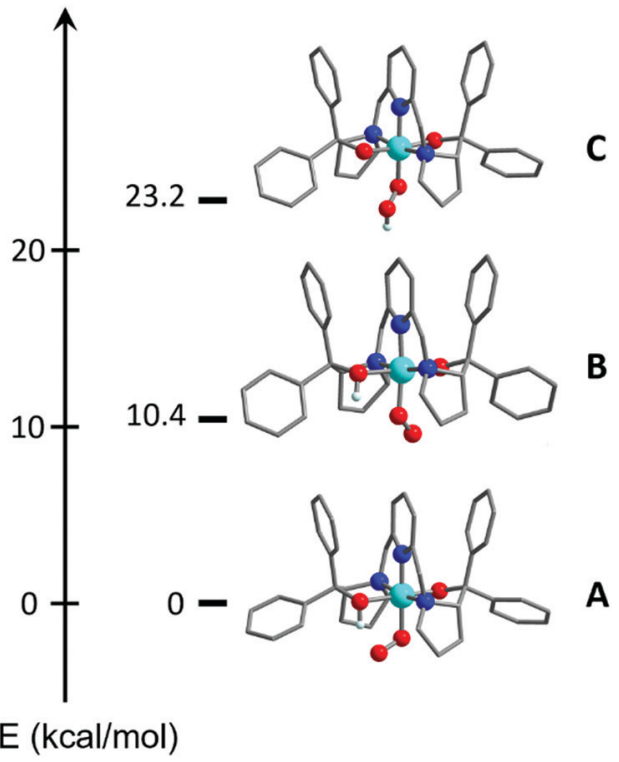

Fig. 3 Computed models for 2.

During this process, we did not observe the formation of $\mathrm{Co}^{\mathrm{III}}$ hydroperoxo 3. Instead, the reaction produced $19 \%$ of $\mathrm{H}_{2} \mathrm{O}_{2}$ with respect to 1 , as determined by iodometric titration (Fig. S5, ESI $\dagger$ ). When 2 equiv. of HOTf was added, $42 \%$ of $\mathrm{H}_{2} \mathrm{O}_{2}$ was furnished (Fig. S6, ESI $\dagger$ ). Thus, we reasoned that the aforementioned reaction indeed generates 3 ; however, once formed, 3 further reacted with HOTf to produce $\mathrm{H}_{2} \mathrm{O}_{2}$. On the other hand,

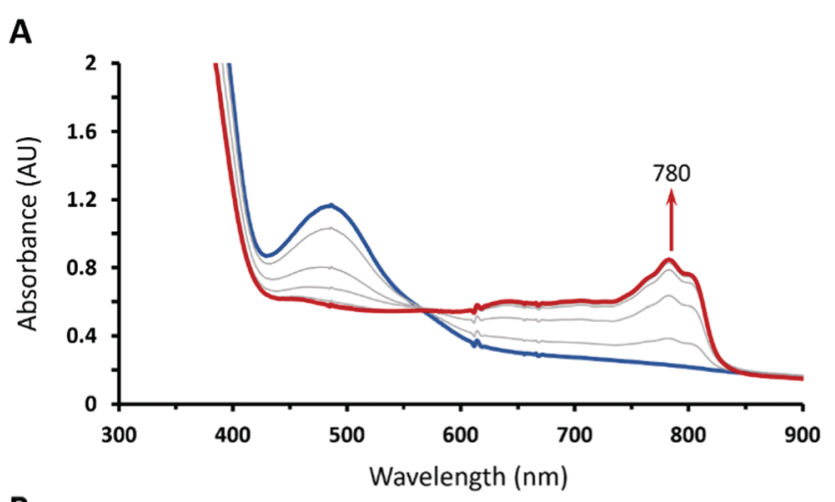

B

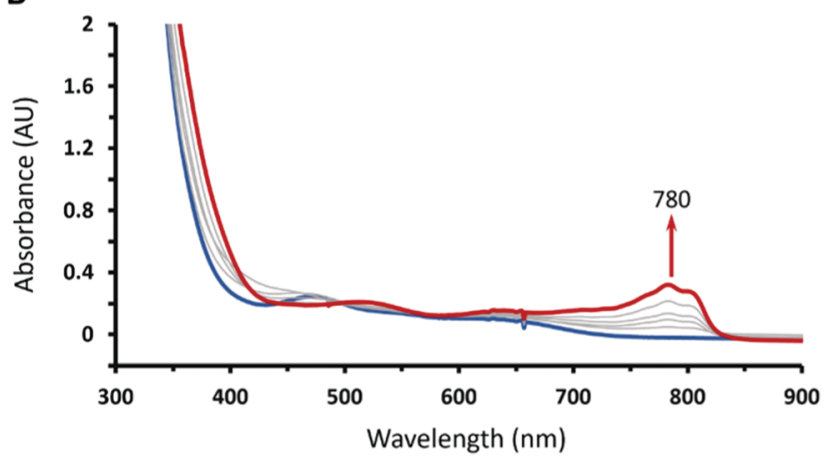

Fig. 4 UV-vis spectral changes of addition of (A) 1 equiv. of HOTf into a solution of $1(1.0 \mathrm{mM})$ in the presence of 1 equiv. of $\mathrm{Cp}^{*}{ }_{2} \mathrm{Fe}$ and (B) 1 equiv. of $\mathrm{Cp}_{2}{ }_{2} \mathrm{Fe}$ into a solution of $\mathbf{2}(1.0 \mathrm{mM})$ in $\mathrm{THF}$ at $-90{ }^{\circ} \mathrm{C}$. treating 2 with 1 equiv. of $\mathrm{Cp}_{2}{ }_{2} \mathrm{Fe}$ (Fig. $4 \mathrm{~B}$ ) also generated $23 \%$ of $\mathrm{H}_{2} \mathrm{O}_{2}$ (Fig. S7, ESI $\dagger$ ). Therefore, all experimental findings revealed that transformation of $\mathbf{1}$ to $\mathbf{3}$ proceeds via concerted proton coupled electron transfer, which clearly demonstrated the ambiphilicity of $\mathbf{1 .}$

Reaction of 1 with $\mathrm{Sc}(\mathrm{OTf})_{3}$ in THF at $-90{ }^{\circ} \mathrm{C}$ generated a product, which showed nearly identical absorption and EPR spectra to those of 2 (Fig. S8 (ESI $\dagger$ ) and Fig. 2D). On the basis of these observations, we tentatively suggest that the reaction furnished a $\mathrm{Co}^{\mathrm{III}}$-superoxo $\cdots \mathrm{Sc}^{\mathrm{III}}$ species, $\left[\mathrm{Co}(\mathrm{BDPP})\left(\mathrm{O}_{2}{ }^{\bullet}\right) \cdots \mathrm{Sc}(\mathrm{OTf})_{n}\right]^{(3-n)+}(\mathbf{4})$. Furthermore, addition of $\mathrm{Sc}(\mathrm{OTf})_{3}$ to the mixture of 1 and $\mathrm{Cp}^{*}{ }_{2} \mathrm{Fe}$ in THF at $-90{ }^{\circ} \mathrm{C}$ afforded a Co ${ }^{\mathrm{III}}$-peroxo-Sc ${ }^{\mathrm{III}}$ complex, [Co(BDPP) $\left.(\mu-\mathrm{OO}) \mathrm{Sc}(\mathrm{OTf})_{\mathrm{n}}\right]^{(2-n)+}(5)$, as depicted in Scheme 1 (Fig. S9, ESI $\dagger$ ). Addition of 2 equiv. of HOTf to the THF solution of 5 produced $76 \%$ $\mathrm{H}_{2} \mathrm{O}_{2}$ as quantified by iodometric titration experiments (Fig. S10, ESI $\dagger$ ). Formation of $\mathrm{H}_{2} \mathrm{O}_{2}$ thus strongly supports the identity of peroxo-bridged binuclear 5. These findings further reinforce the ambiphilic property of $\mathbf{1}$.

In comparison with the similar reaction found for $\mathrm{Mn}^{\mathrm{III}}$ $\left(\mathrm{BDP}^{\mathrm{Br}} \mathrm{P}\right)\left(\mathrm{O}_{2}^{\bullet}\right)$ (Scheme 1), the difference can be readily attributed to the much higher oxidation potential of $\mathrm{Co}^{\mathrm{III}}$ to $\mathrm{Co}^{\mathrm{IV}}$ than that of $\mathrm{Mn}^{\mathrm{III}}$ to $\mathrm{Mn}^{\mathrm{IV}}$, which can ultimately be rooted back to the distinct effective nuclear charge of low spin $\mathrm{Co}^{\mathrm{III}}$ compared to high spin $\mathrm{Mn}^{\mathrm{III}}$ centers. Therefore, formation of an otherwise hydroperoxo $\mathrm{O}-\mathrm{H}$ bond does not provide a sufficient driving force to trigger an electron transfer from the $\mathrm{Co}^{\mathrm{III}}$ center to the superoxo ligand. Consequently, the superoxo motif is not electron rich enough to accommodate the incoming proton from HOTf and protonation of the supporting $\mathrm{BDPP}^{2-}$ ligand is preferred. Therefore, to effect surperoxo-to-peroxo conversion for $\mathbf{1}$, an external electron source has to be provided in addition to Brønsted or Lewis acids.

In conclusion, treatment of $\mathrm{Co}^{\mathrm{III}}$-superoxo 1 with HOTf and $\mathrm{Sc}(\mathrm{OTf})_{3}$ afforded the ligand-protonated $\mathrm{Co}^{\mathrm{III}}$-superoxo 2 with a hydrogen bond formed between the $\mathrm{O}_{2}{ }^{--}$motif and the protonated $\mathrm{BDPP}^{2-}$ ligand and a superoxo-bridged binuclear $\mathrm{Co}^{\mathrm{III}} / \mathrm{Sc}^{\mathrm{III}}$ 4 , and $\mathrm{Co}^{\mathrm{III}}$-superoxo 1 can be regenerated from deprotonation of 2 by DBU. However, addition of 2 equiv. of HOTf into the reaction mixture of 1 and $\mathrm{Cp}_{2}{ }_{2} \mathrm{Fe}$ produced $42 \%$ of $\mathrm{H}_{2} \mathrm{O}_{2}$ suggesting the formation of $\mathrm{Co}^{\mathrm{III}}$-hydroperoxo 3 , and the reaction of $\mathrm{Sc}(\mathrm{OTf})_{3}$ with 1 in the presence of $\mathrm{Cp}^{*}{ }_{2} \mathrm{Fe}$ gave a peroxo-bridged binuclear $\mathrm{Co}^{\mathrm{III}} / \mathrm{Sc}^{\mathrm{III}} 5$. These findings provided strong experimental support for the ambiphilic property of $\mathrm{Co}^{\mathrm{III}}$-superoxo 1 . Interestingly, the ligand-protonated $\mathrm{Co}^{\text {III }}$-superoxo 2 can be prepared from oneelectron oxidation of $\mathrm{Co}^{\text {III }}$-hydroperoxo 3 . The unveiled results underline the critical property of ambiphilicity for metal-superoxo species and direct us to design further investigation strategies towards better understanding $\mathrm{O}_{2}$ activation processes carried out by metalloenzymes and related catalysts.

We are grateful for the financial supports from the Ministry of Science and Technology of Taiwan (MOST 108-2113-M-003009-MY3 to W.-Z. L.) and the Max-Planck Society. W.-Z. L. and S. Y. also acknowledge the MOST-DAAD Project-Based Personnel Exchange Program (MOST 107-2911-I-003-502 and DAAD 57320810). Open Access funding provided by the Max Planck Society. 


\section{Conflicts of interest}

There are no conflicts to declare.

\section{Notes and references}

1 (a) E. G. Kovaleva and J. D. Lipscomb, Nat. Chem. Biol., 2008, 4, 186-193; (b) M. Costas, M. P. Mehn, M. P. Jensen and L. Que, Chem. Rev., 2004, 104, 939-986; (c) A. J. Jasniewski and L. Que, Jr., Chem. Rev., 2018, 118, 2554-2592; (d) C. E. Elwell, N. L. Gagnon, B. D. Neisen, D. Dhar, A. D. Spaeth, G. M. Yee and W. B. Tolman, Chem. Rev., 2017, 117, 2059-2107; (e) K. Ray, F. F. Pfaff, B. Wang and W. Nam, J. Am. Chem. Soc., 2014, 136, 13942-13958; $(f)$ S. Sahu and D. P. Goldberg, J. Am. Chem. Soc., 2016, 138, 11410-11428.

2 (a) M. H. Dickman and M. T. Pope, Chem. Rev., 1994, 94, 569-584; (b) S. Fukuzumi, Y. M. Lee and W. Nam, Dalton Trans., 2019, 48, 9469-9489; (c) H. Noh and J. Cho, Coord. Chem. Rev., 2019, 382, 126-144; (d) X. Cai, S. Majumdar, G. C. Fortman, C. S. J. Cazin, A. M. Z. Slawin, C. Lhermitte, R. Prabhakar, M. E. Germain, T. Palluccio, S. P. Nolan, E. V. Rybak-Akimova, M. Temprado, B. Captain and C. D. Hoff, J. Am. Chem. Soc., 2011, 133, 1290-1293; (e) R. Huacuja, D. J. Graham, C. M. Fafard and C.-H. Chen, J. Am. Chem. Soc., 2011, 133, 3820-3823; $(f)$ X. Zhang, G. R. Loppnow, R. McDonald and J. Takats, J. Am. Chem. Soc., 1995, 117, 7828-7829.

3 (a) S. Herold and W. H. Koppenol, Coord. Chem. Rev., 2005, 249, 499-506; (b) R. D. Harcourt, Coord. Chem. Rev., 2018, 358, 178-180; (c) P. R. Gardner, A. M. Gardner, L. A. Martin and A. L. Salzman, Proc. Natl. Acad. Sci. U. S. A., 1998, 95, 10378-10383; (d) A. K. Das and M. Meuwly, Angew. Chem., Int. Ed., 2018, 57, 3509-3513; (e) S. K. Sharma, A. W. Schaefer, H. Lim, H. Matsumura, P. Moënne-Loccoz, B. Hedman, K. O. Hodgson, E. I. Solomon and K. D. Karlin, J. Am. Chem. Soc., 2017, 139, 17421-17430; $(f)$ R. Cao, L. T. Elrod, R. L. Lehane, E. Kim and K. D. Karlin, J. Am. Chem. Soc., 2016, 138, 16148-16158; $(g)$ J. J. Liu, M. A. Siegler, K. D. Karlin and P. Moenne-Loccoz, Angew. Chem., Int. Ed., 2019, 58, 10936-10940.

4 (a) E. G. Kovaleva and J. D. Lipscomb, Science, 2007, 316, 453; (b) P. Kumar, S. V. Lindeman and A. T. Fiedler, J. Am. Chem. Soc., 2019, 141, 10984-10987.

5 (a) M. N. Blakely, M. A. Dedushko, P. C. Yan Poon, G. Villar-Acevedo and J. A. Kovacs, J. Am. Chem. Soc., 2019, 141, 1867-1870; (b) A. Kunishita, M. Kubo, H. Sugimoto, T. Ogura, K. Sato, T. Takui and S. Itoh, J. Am. Chem. Soc., 2009, 131, 2788-2789; (c) R. L. Peterson, R. A. Himes, H. Kotani, T. Suenobu, L. Tian, M. A. Siegler, E. I. Solomon, S. Fukuzumi and K. D. Karlin, J. Am.
Chem. Soc., 2011, 133, 1702-1705; (d) J. Cho, J. Woo and W. Nam, J. Am. Chem. Soc., 2010, 132, 5958-5959; (e) H. Kelm and H.-J. Krüger, Angew. Chem., Int. Ed., 2001, 40, 2344-2348; $(f)$ E. Tamanaha, B. Zhang, Y. Guo, W.-C. Chang, E. W. Barr, G. Xing, J. St Clair, S. Ye, F. Neese, J. M. Bollinger, Jr. and C. Krebs, J. Am. Chem. Soc., 2016, 138, 8862-8874; $(g)$ N. Kindermann, C.-J. Günes, S. Dechert and F. Meyer, J. Am. Chem. Soc., 2017, 139, 9831-9834.

6 (a) M. T. Kieber-Emmons, J. Annaraj, M. S. Seo, K. M. Van Heuvelen, T. Tosha, T. Kitagawa, T. C. Brunold, W. Nam and C. G. Riordan, J. Am. Chem. Soc., 2006, 128, 14230-14231; (b) S. Yao, E. Bill, C. Milsmann, K. Wieghardt and M. Driess, Angew. Chem., Int. Ed., 2008, 47, 7110-7113; (c) J. Cho, J. Woo and W. Nam, J. Am. Chem. Soc., 2012, 134, 11112-11115; (d) K. Fujita, R. Schenker, W. Gu, T. C. Brunold, S. P. Cramer and C. G. Riordan, Inorg. Chem., 2004, 43, 3324-3326; (e) T. Tano, Y. Okubo, A. Kunishita, M. Kubo, H. Sugimoto, N. Fujieda, T. Ogura and S. Itoh, Inorg. Chem., 2013, 52, 10431-10437; $(f)$ L.-L. Liu, H.-X. Li, L.-M. Wan, Z.-G. Ren, H.-F. Wang and J.-P. Lang, Chem. Commun., 2011, 47, 11146-11148. 7 (a) P. Pirovano, A. M. Magherusan, C. McGlynn, A. Ure, A. Lynes and A. R. McDonald, Angew. Chem., Int. Ed., 2014, 126, 6056-6060; (b) W. D. Bailey, N. L. Gagnon, C. E. Elwell, A. C. Cramblitt, C. J. Bouchey and W. B. Tolman, Inorg. Chem., 2019, 58, 4706-4711.

8 Y.-H. Lin, Y. Kutin, M. van Gastel, E. Bill, A. Schnegg, S. Ye and W.-Z. Lee, J. Am. Chem. Soc., 2020, 142, 10255-10260.

9 (a) S. Ye, C. Riplinger, A. Hansen, C. Krebs, J. M. Bollinger, Jr. and F. Neese, Chem. - Eur. J., 2012, 18, 6555-6567; (b) T. Borowski, A. Bassan and P. E. M. Siegbahn, Chem. - Eur. J., 2004, 10, 1031-1041.

10 (a) W. D. Bailey, D. Dhar, A. C. Cramblitt and W. B. Tolman, J. Am. Chem. Soc., 2019, 141, 5470-5480; (b) S. Hong, K. D. Sutherlin, J. Park, E. Kwon, M. A. Siegler, E. I. Solomon and W. Nam, Nat. Commun., 2014, 5, 5440-5547; (c) M. Sankaralingam, Y.-M. Lee, W. Nam and S. Fukuzumi, Coord. Chem. Rev., 2018, 365, 41-59; (d) A. R. Corcos, O. Villanueva, R. C. Walroth, S. K. Sharma, J. Bacsa, K. M. Lancaster, C. E. MacBeth and J. F. Berry, J. Am. Chem. Soc., 2016, 138, 1796-1799.

11 (a) C. W. Chiang, S. T. Kleespies, H. D. Stout, K. K. Meier, P. Y. Li, E. L. Bominaar, L. Que, Jr., E. Munck and W. Z. Lee, J. Am. Chem. Soc., 2014, 136, 10846-10849; (b) C. C. Wang, H. C. Chang, Y. C. Lai, H. Fang, C. C. Li, H. K. Hsu, Z. Y. Li, T. S. Lin, T. S. Kuo, F. Neese, S. Ye, Y. W. Chiang, M. L. Tsai, W. F. Liaw and W. Z. Lee, J. Am. Chem. Soc., 2016, 138, 14186-14189; (c) Y. H. Lin, H. H. Cramer, M. van Gastel, Y. H. Tsai, C. Y. Chu, T. S. Kuo, I. R. Lee, S. Ye, E. Bill and W. Z. Lee, Inorg. Chem., 2019, 58, 9756-9765. 